\title{
DIAGNÓSTICO E TRATAMENTO DE PONTOS GATILHOS MIOFASCIAS - RELATO DE CASO
}

Lucas Kleber CAZULA LOPES, Wagner SIMM

Clinicamente o ponto gatilho é um ponto de sensibilidade localizado em um nódulo, em uma banda tensa palpável de fibras musculares. Nos pontos gatilhos ativos a queixa de dor é regional e mal localizada, e aumenta quando são digitalmente comprimidos. A ativação de um ponto gatilho esta associado à sobrecarga muscular que pode ser de forma aguda, sustentada, repetitiva, por outro ponto gatilho, doenças viscerais, articulações artríticas ou stress. Os músculos mais frequentemente afetados por pontos gatilhos ativos são os posturais do pescoço, ombro, cintura pélvica e da mastigação, podendo gerar dois tipos de disfunção: autonômicas ou motoras. $O$ tratamento de pontos gatilhos consiste basicamente em identificar $a(s)$ causa(s) e os fatores perpetuantes, ajudando o paciente a restaurar e manter a função muscular normal. O presente trabalho tem como objetivo relatar um caso clínico de diagnóstico e tratamento de pontos gatilhos através do rompimento mecânico promovido pelo agulhamento seco, em um paciente diagnosticado com dor miofascial com limitação de abertura, através do Research Diagnostic Criteria. Após três sessões de acompanhamento clinico da terapia proposta, o paciente se encontra sob controle, com melhora total dos sinais e sintomas identificados no exame clinico inicial.

Palavras-chave: Dor Facial; Síndrome da Disfunção da Articulação Temporomandibular; Trismo. 